\title{
On the nature of the longitudinal anomaly of the southern hemisphere lower stratospheric temperature
}

\author{
Luis Eduardo Antunes Vieira ${ }^{1}$ and Ligia Alves da Silva ${ }^{2}$ \\ ${ }^{1}$ Max-Planck-Institut für Sonnensystemforschung, 37191 Katlenburg-Lindau, Germany \\ email: vieira@mps.mpg.de \\ ${ }^{2}$ Instituto Nacional de Pesquisas Espaciais, 12227-010 Sao Jose dos Campos, Brazil \\ email: dasilva@mps.mpg.de
}

\begin{abstract}
The effects of changes in the solar radiative emission on ozone levels in the stratosphere have been considered as a candidate to explain the link between solar activity and its effects on the climate. As ozone absorbs electromagnetic radiation, changes in ozone concentrations alter Earth's radiative balance by modifying both incoming solar radiation and outgoing radiation. In this way, ozone controls solar energy deposition in the stratosphere and its variations alter the thermal structure of the stratosphere. These changes are assumed to propagate downward through a chain of feedbacks involving thermal and dynamical processes. The effects of high energy particle precipitation on mesospheric and stratospheric ozone have also been investigated. However, while the effects of high energy particle precipitation on ozone distribution in the auroral region has been investigated during the last decades, little is known about the role of the high energy particle precipitation on the stratospheric composition and thermal structure in the tropical/subtropical region. Here we show that the spatial distribution of the lower stratosphere temperature is affected by the presence of the southern hemisphere magnetic anomaly. We found that during the austral winter and spring, in the subtropical region (below 30 deg $\mathrm{S})$, the reduction of the lower stratosphere temperature occurs systematically in the magnetic anomaly area. This result is consistent with the observations that in the southern hemisphere subtropical region the energy of precipitating particles is deposited lower in altitude in regions with weaker magnetic field intensity.
\end{abstract}

Keywords. Climate Change, Lower Stratosphere Temperature, Space Weather

\section{Introduction}

The increase of the surface temperature during the last century is the most important evidence that the Earths climate is changing. However, the increase of the surface temperature is not uniform (see Fig. 1). A large increase of the surface temperature is observed in the North Hemisphere over the continents. Regions without changes or reductions in the temperature are observed in the Pacific and Atlantic Oceans. Most of the changes of the surface temperature are closely related to changes of the regional atmospheric and oceanic circulation patterns.

Several authors argue that the changes of the atmospheric and oceanic patterns are related to the increase of the emission of greenhouse gases due to the anthropogenic activity. One strong argument is that the solar activity during the last 30 years is not increasing while a rapid increase of the surface temperature is observed. However, there are large uncertainties of natural and anthropogenic forcings of climate change. For example, the long-term variability of the total and spectral solar electromagnetic emission are not known. 
Recently, a link between changes of the Walker circulation in the South Pacific and the westward drift of the Southern Hemisphere Magnetic Anomaly (SHMA), a region of low magnetic field intensity over South America and adjacent oceans, was proposed. Many interesting and significant atmospheric circulation features, such as the ENSO phenomena, are observed in the equatorial and southern low-latitude regions of the Pacific Ocean (e.g., Vincent 1994, and references therein). Two important large-scale features that occur in the Pacific SHMA region are: the Intertropical Convergence Zone (ITCZ), and the South Pacific Convergence Zone (SPCZ). In this paper, we use the effects of long-wavelength (LW) cloud effects, on the radiative flux in the atmosphere to indicate tropical convection and rainfall. In order to study the effects on the radiative flux in the SHMA region, we used the ISCCP D2 data (Rossow \& Schiffer 1991). Figure 2 shows the distribution of LW cloud effects for December and June, averaged from 19832004. Positive values indicate energy input and negative values indicating energy loss. The convective precipitation is observed in the heating regions. The superimposed black lines in Figure 3 show the iso-intensity contours of the geomagnetic field at $10 \mathrm{~km}$ in the region of the magnetic anomaly for year 1990. The geomagnetic field was estimated using the International Geomagnetic Reference Field (IGRF) model [IAGA, Division V, Working Group VMOD, 2005]. We used in this paper the magnetic field parameters in order to identify the magnetic anomaly region. In December, the axis of heating stretches eastward, along $5^{\circ}-10^{\circ} \mathrm{S}$, from the eastern Indian Ocean to $180^{\circ} \mathrm{W}$. It then extends southeastward toward higher latitudes, to about $45^{\circ} \mathrm{S}, 130^{\circ} \mathrm{W}$. West of the $180^{\circ}$ meridian, the near-zonal band of convection is commensurate with the ITCZ. East of the $180^{\circ}$ meridian, the diagonal cloud band is referred to as the SPCZ. In December, it is most intense and extends farther poleward. The SPCZ cloud band is confined between the 0.35 to 0.45 Gauss iso-intensity contours of the geomagnetic field. In June, the ITCZ cloud band has shifted into the Northern Hemisphere; the axis of minimum values of LW cloud effects stretches from Southeast Asia to $10^{\circ} \mathrm{N}$, near $140^{\circ} \mathrm{E}$, and then generally eastward across the entire Pacific Ocean. The cloud band associated to the SPCZ extends to approximately $10^{\circ} \mathrm{S}$ also confined in the 0.35 to 0.42 Gauss iso-intensity contours of the geomagnetic field.

The authors speculated that the physical mechanism should involve effects of particle precipitation in the magnetic anomaly region on the thermal structure of the

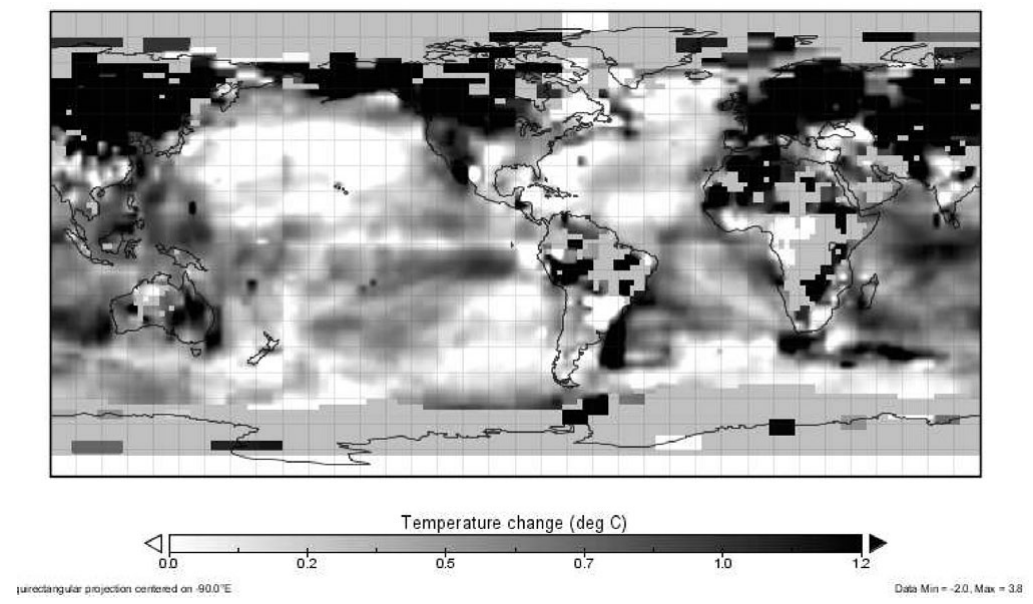

Figure 1. Surface temperature trend from 1951 to 2007. Source: Goddard Institute for Space Studies (GISS) Surface Temperature Analisis. 
(a)
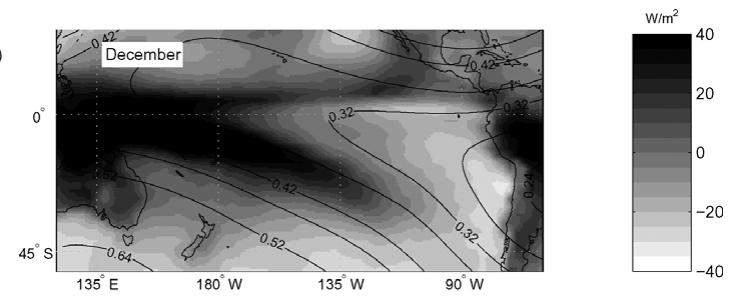

(b)
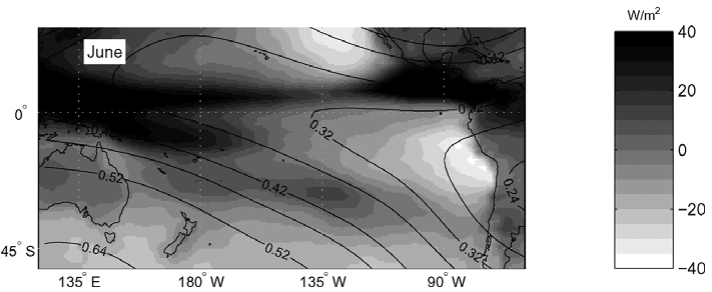

Figure 2. Long-wavelength cloud effects on the net radiative flux in the atmosphere for (a) December and (b) June, averaged for the years 1983-2001. The superimposed black lines show the iso-intensity contours of the geomagnetic field near the surface $(10 \mathrm{~km})$ for year 1990 .

stratosphere. The effects of changes in the solar radiative emission and particle precipitation on ozone levels in the stratosphere have been considered as a candidate to explain the link between solar activity and its effects on the Earths atmospheric composition and thermal structure (e.g., Cubasch \& Voss 2000, Randal et al. 2006). Pinto et al. (1990) estimated that the ozone depletion due to electron precipitation at $70-80 \mathrm{~km}$ in the Southern Hemisphere Magnetic Anomaly (SHMA) region during large geomagnetic storms can be as much as $30 \%$. Estimatives of the ionization rate due to electron precipitation in middle latitude suggests a peak near 75-90 km altitude due to primary electron energy deposition, whereas the secondary peaks near $35-45 \mathrm{~km}$ are due to Bremsstrahlung X ray penetration (Vampola \& Gorney 1983). In the SHMA region the precipitation penetrates deeper in the atmosphere and can lead to more enhanced ionization from Bremsstrahlung at low altitudes. From this estimative, the ionization rate from the Bremsstrahlung X ray penetration is about four orders of magnitude smaller than the primary electrons. Balloon-born X-ray measurements have detected energetic electron precipitation effects at stratospheric heights during intense magnetic disturbances (e.g., Pinto \& Gonzalez 1986, Pinto \& Gonzalez 1989).

The effects of the zonal asymmetry in the ozone on climate have been examined in the Northern and Southern Hemispheres. These analyses suggest that changes in the zonal asymmetry of ozone have had important impacts on Southern Hemisphere Climate (Crook et al. 2008, Vieira et al. 2008). In the next section we compare the patterns of the lower stratosphere temperature with the configuration of the Earth's magnetic fiels in the South Hemisphere. The results presented are discussed in detail by Da Silva et al. (2008).

\section{Southern hemisphere lower stratospheric temperature}

In order to estimate the monthly lower stratosphere temperature climatology, we used monthly distributions of the lower stratosphere temperature (TLS channels) obtained by Microwave Sounding Units (MSU) operating on nine NOAA polar-orbiting platforms from 1979 to 2007. The weighting function for the TLS channel peaks between 15 and 
$20 \mathrm{~km}$ of altitude. Warming events caused by the eruptions of El Chichon (1982) and Mt Pinatubo (1991) were observed during the analyzed period.

Figure 3 presents the southern hemisphere lower stratosphere brightness temperature climatology for June to November, estimated from 1979 to 2005. The atmospheric temperature varies with altitude according to chemical and physical processes taking place. In the lower stratosphere air is transported from the tropics towards the poles by the Brewer-Dobson circulation. In this region, the upper tropospheric convective processes affect the tropics so that the temperature has a minimum near the equator and maxima at the summer pole and in winter mid-latitudes. In the upper stratosphere and mesosphere there is a solstitial circulation with upward motion in the summer hemisphere, a summer-to-winter transport in the mesosphere and descent near the winter pole. Following Grytsai et al. (2007), we focus on these months, as this is generally when both the chemical and dynamical contributions to the zonal ozone asymmetry act, and transport processes associated with the break-down of the polar vortex are less important. The superimposed black lines in Figure 3 show the iso-intensity contours of the geomagnetic
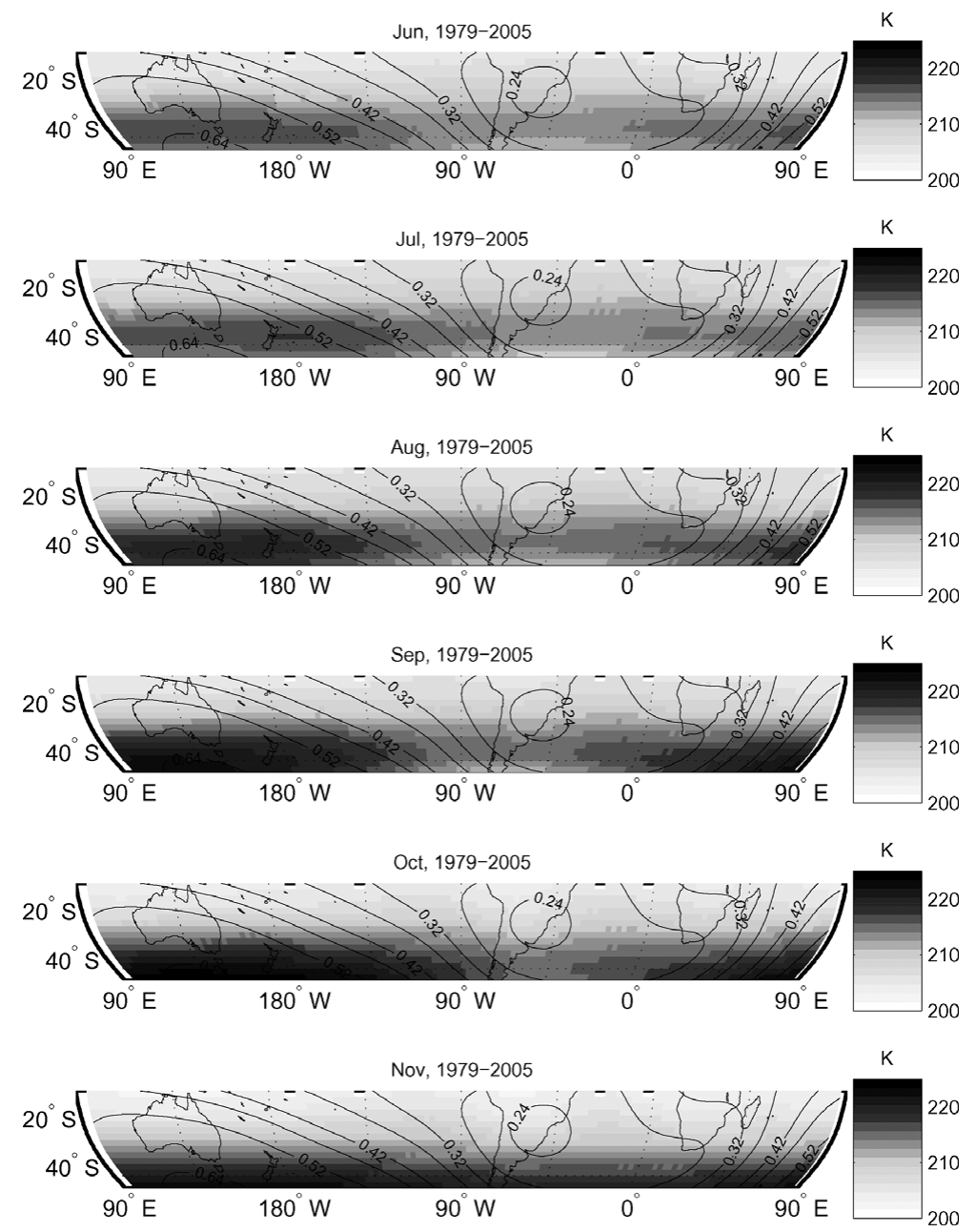

Figure 3. Southern hemisphere lower stratosphere temperature climatology for June to November. The superimposed black lines show the iso-intensity contours of the geomagnetic field at $10 \mathrm{~km}$ for year 1990. After Da Silva et al. 2008 
field at $10 \mathrm{~km}$ in the region of the magnetic anomaly for year 1990. For the purpose of this analysis the boundaries of the magnetic anomaly were not fixed.

We note a large reduction of the temperature in the region of the magnetic anomaly in the belt between $60^{\circ} \mathrm{S}$ and $30^{\circ} \mathrm{S}$ during the austral winter and spring, while during the austral summer (not shown here) the reduction in the temperature is not noticeable. This reduction of the temperature coincides quite well with the region which presents higher electron flux. The maximum difference between the temperatures inside the magnetic anomaly $\left(60^{\circ} \mathrm{W}\right)$ and outside the anomaly $\left(150^{\circ} \mathrm{E}\right)$ for the latitude of $42.5^{\circ} \mathrm{S}$ is approximately $5.9 \mathrm{~K}$ and occurs in October during the austral spring.

\section{Conclusions}

During the austral winter and spring, in the subtropical region (below $30^{\circ} \mathrm{S}$ ), the reduction of the lower stratosphere temperature occurs systematically in the magnetic anomaly area. This result is consistent with the assumption that in the subtropical region the energy of precipitating particles is deposited lower in altitude in regions with weaker magnetic field intensity. However, from this analysis it is not possible to distinguish if the effects of particle precipitation occur in the lower stratosphere or, most probably, in the lower mesosphere/upper stratosphere propagating downward.

\section{References}

Crook, J. A., Gillett, N. P., \& Keeley, S. P. E. 2008, Geophys. Res. Lett., 35, L07806, doi:10.1029/2007GL032698.

Cubasch, U. \& Voss, R. 2000, Space Science Reviews, 94(1-2), 185-198.

Da Silva, L. A., Vieira, L. E. A., Echer, E., \& Satyamurty, P. 2008, JASTP, submitted.

Gledhill, J. A. 1976, Reviews of Geophysics, 14 (2), 173-187.

Grytsai, A. V., Evtushevsky, O. M., Agapitov, O. V., Klekociuk, A. R., \& Milinevsky, G. P. 2007, Ann. Geophys., 25, 361-374.

Pinto, O. \& Gonzalez, W. D. 1986, Journal of Geophysical Research, 91(A6), 7072-7078.

Pinto, O. \& Gonzalez, W. D. 1989, Journal of Atmospheric and Terrestrial Physics, 51(5), $351-365$.

Pinto, O., Kirchhoff, V., \& Gonzalez, W. D. 1990, Annales Geophysicae-Atmospheres Hydrospheres and Space Sciences, 8 (5), 365-367.

Randall, C. E., et al. 2006, Geophysical Research Letters, 33.

Rossow, W. B. \& Schiffer, R. A. 1991, Bulletin of the American Meteorological Society, 72, 2-20.

Vampola, A. \& Gorney, D. 1983, J. Geophys. Res., 88 (A8), 6267-6274.

Vieira, L. E. A. \& da Silva, L. A. 2006, Geophys. Res. Lett., 33, L14802, doi:10.1029/2006GL026389.

Vieira, L. E. A., da Silva, L. A., \& Guarnieri, F. L. 2008, J. Geophys. Res., 113, A08226, doi:10.1029/2008JA013052.

Vincent, D. G. 1994, Monthly Weather Review, 122, 1949-1970.

\section{Discussion}

DAVILA: Is there a physical mechanism to explain the magnetic field correlations you showed?

VIEIRA: The physical mechanism seems to be related to changes of the atmosphere composition and thermal structure due to particle precipitation in the magnetic anomaly region. 